\title{
Stepped Cylindrical Antenna with a Higher-Order Mode Ring Patch for Wideband Conical Radiation Pattern
}

\author{
Jinpil Tak, Do-Gu Kang, and Jaehoon Choi \\ Department of Electronics and Communications Engineering, Hanyang University, 17 Haengdang-dong, \\ Seongdong-gu, Seoul 133-791, Republic of Korea \\ Correspondence should be addressed to Jaehoon Choi; choijh@hanyang.ac.kr
}

Received 25 March 2015; Accepted 10 May 2015

Academic Editor: Chih-Hua Chang

Copyright (C) 2015 Jinpil Tak et al. This is an open access article distributed under the Creative Commons Attribution License, which permits unrestricted use, distribution, and reproduction in any medium, provided the original work is properly cited.

\begin{abstract}
A stepped cylindrical antenna with a higher-order mode ring patch for wideband conical radiation pattern is proposed. To accomplish a low profile with wideband conical radiation characteristics, a stepped cylindrical monopole and a $\mathrm{TM}_{41}$ higher-order mode ring patch with four shorting pins are utilized. The proposed antenna has a monopole-like radiation pattern with a wide $10-\mathrm{dB}$ return loss bandwidth of $11 \mathrm{GHz}(2 \mathrm{GHz}-13 \mathrm{GHz})$. It can cover various wireless services, such as wireless broadband (WiBro; $2.3 \mathrm{GHz}-2.39 \mathrm{GHz}$ ), wireless local area networks (WLAN; $2.4 \mathrm{GHz}-2.484 \mathrm{GHz}, 5.15 \mathrm{GHz}-5.35 \mathrm{GHz}$, and $5.725 \mathrm{GHz}-5.875 \mathrm{GHz}$ ), digital multimedia broadcasting (DMB; $2.63 \mathrm{GHz}-2.655 \mathrm{GHz}$ ), and ultra wideband (UWB; $3.1 \mathrm{GHz}-10.6 \mathrm{GHz}$ ). The antenna has a height of only $0.12 \lambda_{0}$ at $2 \mathrm{GHz}$.
\end{abstract}

\section{Introduction}

Monopole antennas are widely used in wireless communications since they are inexpensive and have a simple structure and conical radiation pattern. However, the height of a linear vertical monopole of a quarter wavelength $\left(\lambda_{0} / 4\right)$ is too large for conformal devices [1]. In particular, antennas for vehicle-mounted devices should have a low profile along with monopole-like radiation characteristics [2,3]. To fulfill such requirements, patch antennas with a higher-order mode using shorting posts have been suggested [4-6]. In terms of bandwidth, a thin linear monopole has a very narrow return loss bandwidth. Thus, tiny perturbations in operating frequency owing to environmental change will seriously affect its operational behavior [7]. Therefore, many studies have suggested various methods to enhance the antenna bandwidth, such as use of a rectangular patch antenna with corner slits, a printed monopole with a tapered feed line, a folded monopole, and cylindrical monopoles [8-12]. However, these ultra wideband (UWB) antennas still have a considerable vertical length.

In this letter, a stepped cylindrical antenna with a higherorder mode ring patch for wideband conical radiation pattern is proposed. The proposed antenna has conical radiation patterns with a low profile in the wide operating frequency $(2 \mathrm{GHz}-13 \mathrm{GHz})$ and it covers various wireless services, such as wireless broadband (WiBro; $2.3 \mathrm{GHz}-2.39 \mathrm{GHz}$ ), wireless local area networks (WLAN; $2.4 \mathrm{GHz}-2.484 \mathrm{GHz}, 5.15 \mathrm{GHz}-$ $5.35 \mathrm{GHz}, 5.725 \mathrm{GHz}-5.875 \mathrm{GHz}$ ), digital multimedia broadcasting (DMB; $2.63 \mathrm{GHz}-2.655 \mathrm{GHz}$ ), and UWB $(3.1 \mathrm{GHz}-$ 10.6 GHz).

\section{Antenna Geometry and Design}

The geometry of the proposed wideband antenna is shown in Figure 1. With a height of $18 \mathrm{~mm}\left(0.12 \lambda_{0}\right.$ at $\left.2 \mathrm{GHz}\right)$, the antenna is designed on a ground plane with a radius of $30 \mathrm{~mm}$ $\left(0.2 \lambda_{0}\right.$ at $\left.2 \mathrm{GHz}\right)$. It is composed of a stepped cylindrical monopole for UWB and a $\mathrm{TM}_{41}$ higher-order mode ring patch with four shorting pins, which generates additional resonance to broaden the lower frequency band. The stepped cylindrical monopole consists of an upper cylinder with a radius of $6 \mathrm{~mm}$ and a height of $13 \mathrm{~mm}$, and a lower cylinder with a radius of $2.5 \mathrm{~mm}$ and a height of $3.5 \mathrm{~mm}$. The lower cylinder of the stepped monopole is optimized for broadband impedance matching with the coaxial feed connector having the inner conductor radius of $0.65 \mathrm{~mm}$. The cylindrical monopole is fed by a coaxial cable at the center 


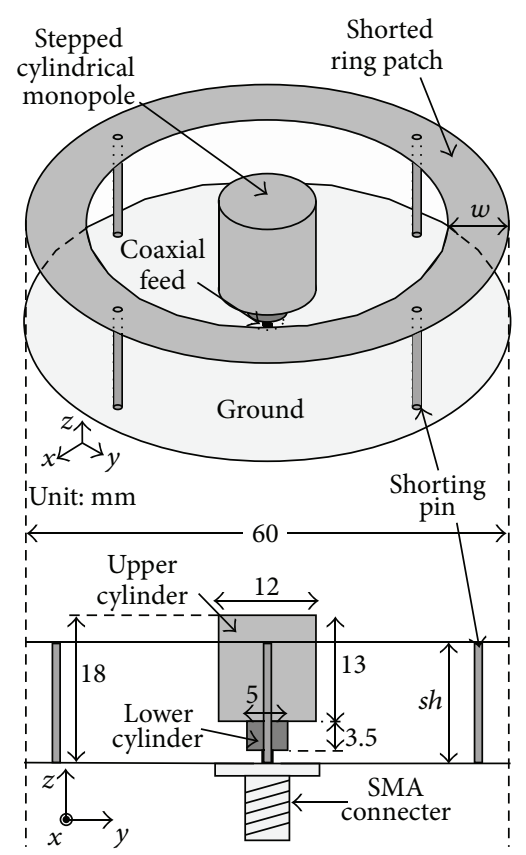

FIGURE 1: Geometry of the proposed wideband antenna.

of the cylinder. To realize additional resonance in the lower frequency band with a conical radiation pattern without increasing the antenna height, an annular ring patch with four shorting pins connected to the ground is designed to generate the $\mathrm{TM}_{41}$ higher-order resonance mode for monopole-like radiation performance [6]. The shorted ring patch has the width of $w \mathrm{~mm}$; the shorting points are positioned at the center of the ring patch with width $w$. Four shorting pins with a radius of $0.4 \mathrm{~mm}$ are symmetrically located at $26 \mathrm{~mm}$ from the center of the feed point. The height of the ring patch and all shorting pins is $s h \mathrm{~mm}$.

Figure 2 shows the simulated return loss characteristics of the antenna with the wideband design procedure from Steps 1 to 3. The color red indicates the added structure at each step. In Step 1, the cylindrical monopole generates the resonance at the lower band-edge frequency; its resonant frequency is given by [7]

$$
f_{L} \approx \frac{72}{L+\mathrm{FG}+R-\mathrm{FR}}(\mathrm{GHz}),
$$

where $L$ is the height of the cylindrical monopole $(L=$ $16.5 \mathrm{~mm}), R$ is the radius of the cylindrical monopole $(R=$ $6 \mathrm{~mm}), \mathrm{FG}$ is the feed gap $(\mathrm{FG}=1.5 \mathrm{~mm})$, and FR represents the radius of the inner conductor of the coaxial connector (FR $=0.65 \mathrm{~mm}$ ). The lower band-edge frequency of the UWB service (about $3.08 \mathrm{GHz}$ ) is derived from these parameters.

In Step 2, a stepped cylindrical monopole is added to realize the broad bandwidth. The upper cylinder and lower cylinder sizes are optimized by simulation. The $10-\mathrm{dB}$ return loss bandwidth is improved from $800 \mathrm{MHz}(3.5 \mathrm{GHz}-$ $4.3 \mathrm{GHz})$ to $15.3 \mathrm{GHz}(3.9-19.2 \mathrm{GHz})$ by using the stepped cylindrical monopole. However, the overall height of the stepped monopole needs to be increased to extend the lower band frequency limit.
In Step 3, a $\mathrm{TM}_{41}$ higher-order mode shorted ring patch is used to generate additional resonance at $2.2 \mathrm{GHz}$ without increasing the overall antenna height. Although the 10$\mathrm{dB}$ return loss bandwidth of the higher frequency band is partially reduced from the $13 \mathrm{GHz}$ to $14 \mathrm{GHz}$ range by adding the shorted ring patch, the proposed antenna fully covers the UWB band. The result indicates that the higher operating band is due to the stepped cylindrical monopole and that the lower operating band is generated by the shorted ring patch. The simulated $10-\mathrm{dB}$ return loss bandwidth of the proposed antenna is $11 \mathrm{GHz}(2 \mathrm{GHz}-13 \mathrm{GHz})$ when width $w$ of the ring patch and height sh of the ring patch and shorting pin are equal to $8 \mathrm{~mm}$ and $13 \mathrm{~mm}$, respectively. It is confirmed that the proposed antenna is suitable for WiBro, 2.4 GHz/5.2 GHz/5.8 GHz WLAN, DMB, and UWB communication services.

Figure 3(a) depicts the simulated return loss characteristics for different values of width $w$ of the shorted ring patch. As $w$ increases, the resonance frequency shifts to a lower frequency and the impedance matching is deteriorated. Considering the $10-\mathrm{dB}$ return loss bandwidth, width $w$ of the shorted ring patch is selected as $8 \mathrm{~mm}$ in this work.

The simulated return loss characteristics for various heights sh of the shorted ring patch and four shorting pins are shown in Figure 3(b). As sh increases, the resonance frequency shifts to a lower frequency and impedance matching improves. However, after $s h=13 \mathrm{~mm}$, the impedance matching is deteriorated and the antenna cannot satisfy the required $10-\mathrm{dB}$ return loss bandwidth. Height sh of the shorting pins and ring patch is optimized as $13 \mathrm{~mm}$ in this design.

Figure 4 illustrates the simulated surface scalar current distributions for various operating frequencies at $2.2 \mathrm{GHz}$, $4 \mathrm{GHz}, 8 \mathrm{GHz}$, and $12 \mathrm{GHz}$. It shows that the upper cylinder 


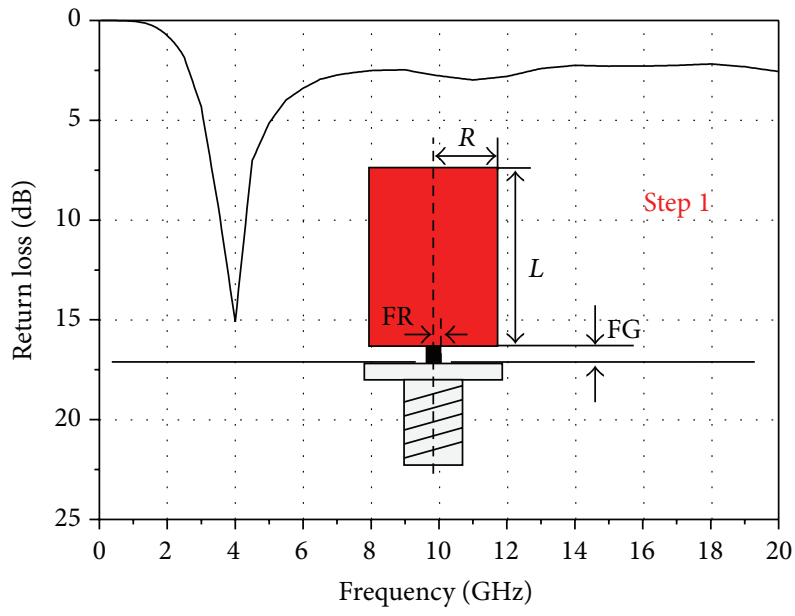

(a)

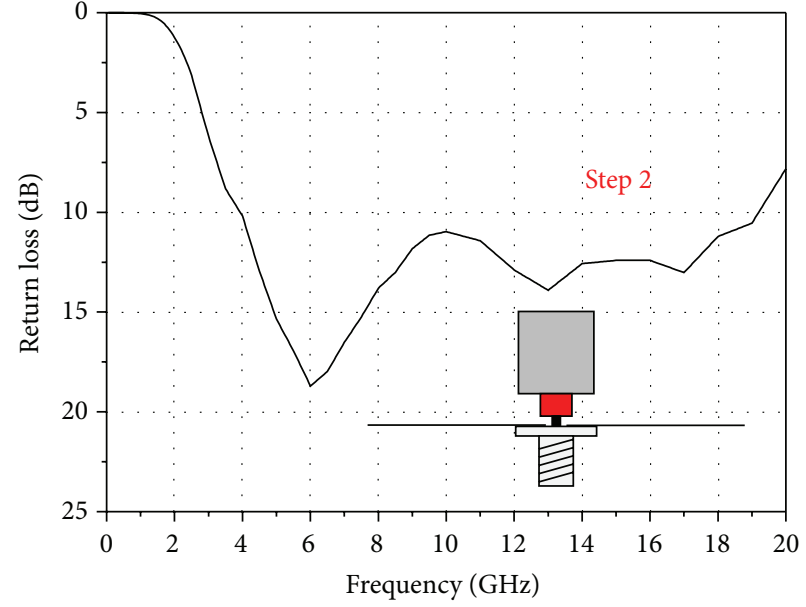

(b)

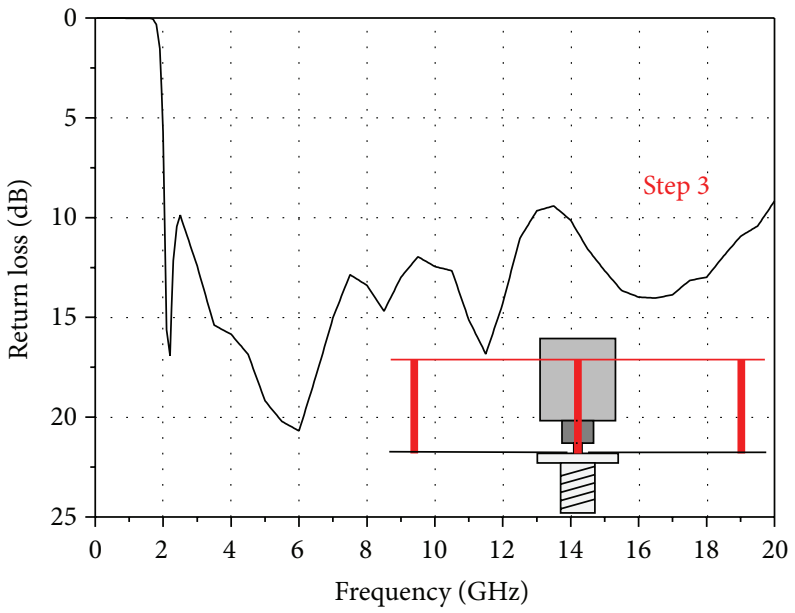

(c)

Figure 2: Simulated return loss characteristics of the antenna and the wideband design procedure from Step 1 (a) to Step 3 (c).

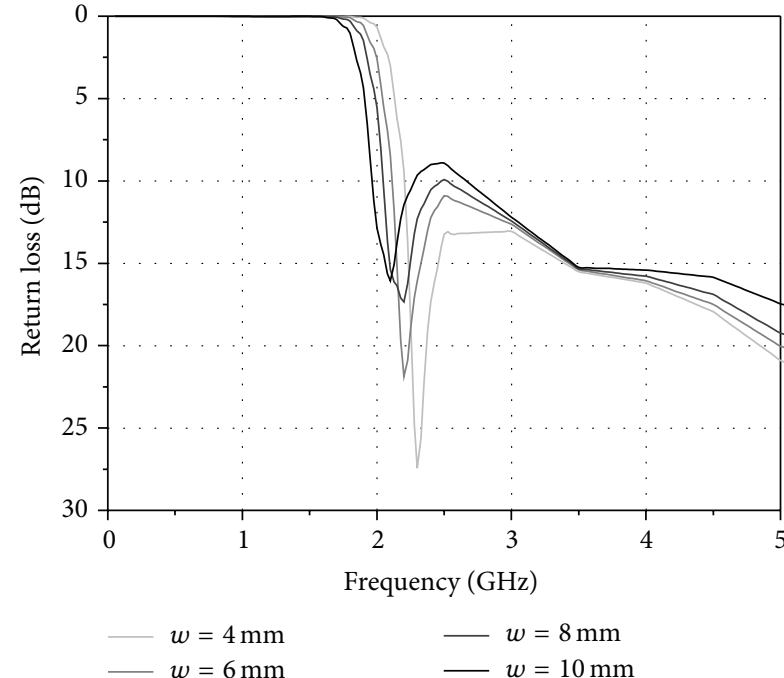

(a)

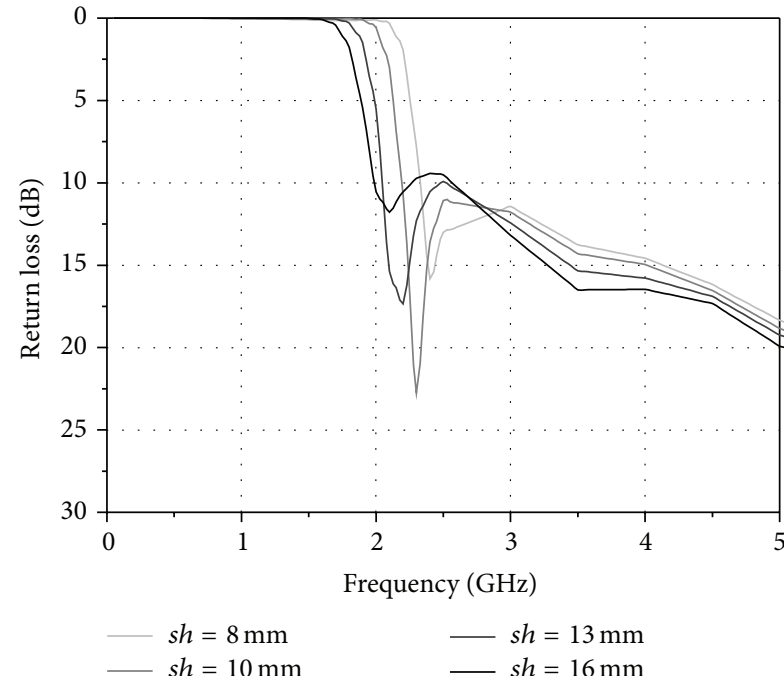

(b)

FIGURE 3: Simulated return loss characteristics for various widths and heights of the shorted ring patch, represented as $w$ and sh, respectively: (a) width $(w)$, (b) height $(s h)$. 


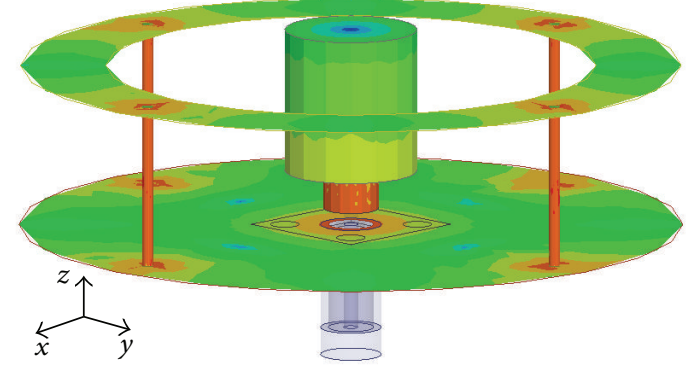

(a)

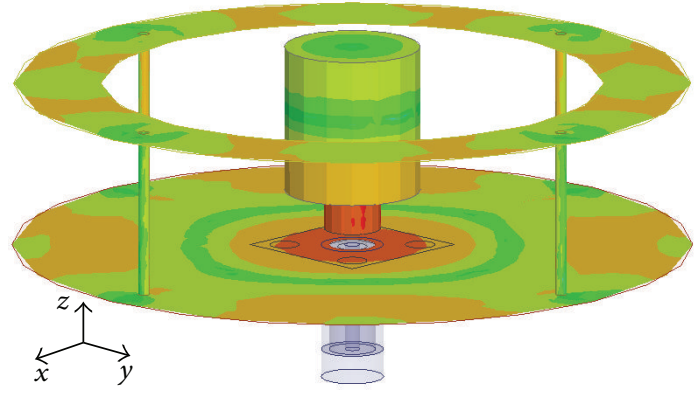

(c)

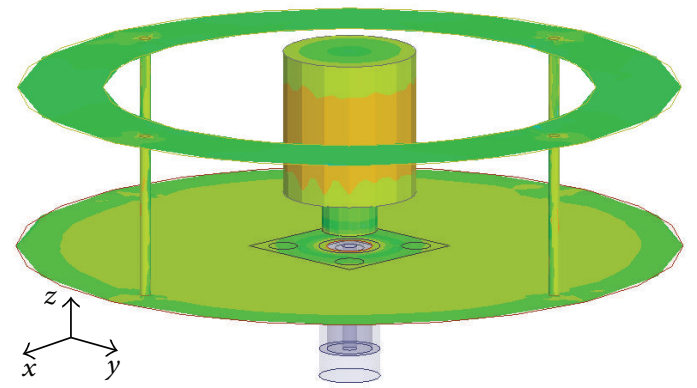

(b)

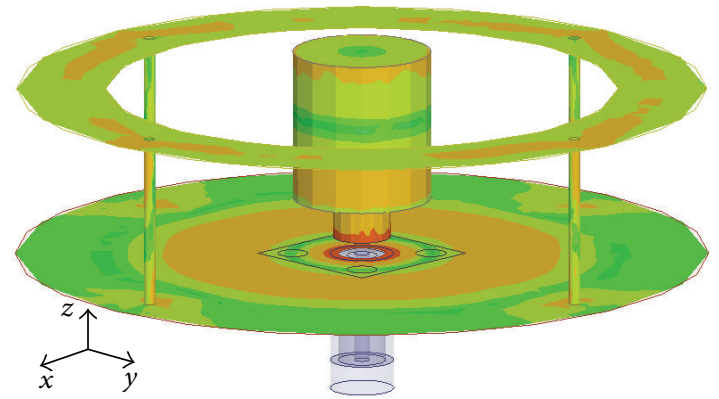

(d)

FIGURE 4: Simulated surface scalar current distributions for various operating frequencies: (a) $2.2 \mathrm{GHz}$, (b) $4 \mathrm{GHz}$, (c) $8 \mathrm{GHz}$, and (d) $12 \mathrm{GHz}$.

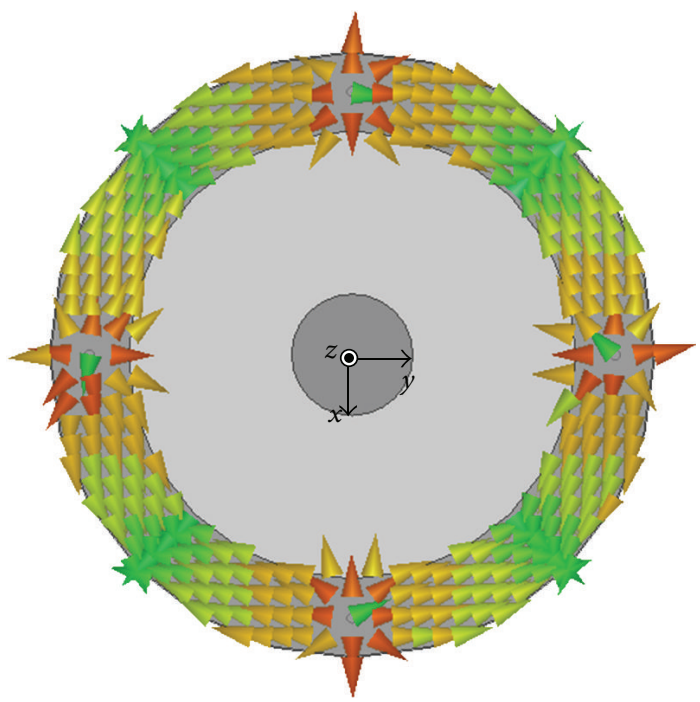

FIGURE 5: Simulated surface vector current distributions on the ring patch at $2.2 \mathrm{GHz}$.

of the stepped cylindrical monopole is operating for the middle frequency band, while the lower cylinder of stepped cylindrical monopole is operating for the higher frequency band. The shorted structure is for the lower frequency band at approximately $2 \mathrm{GHz}$.

The simulated surface vector current distribution on the shorted ring patch at $2.2 \mathrm{GHz}$ is depicted in Figure 5. The fact that the current varies by four cycles along the circumferential direction and by one cycle along the radial direction shows that the antenna is indeed excited by the $\mathrm{TM}_{41}$ higher-order resonance mode for monopole-like radiation [13].

\section{Simulated and Measured Results}

The fabricated prototype of the proposed antenna is shown in Figure 6. To coaxially feed the antenna, the SubMiniature version A (SMA) connector is soldered. The stepped cylindrical monopole is manufactured by cutting the copper cylinder. Figures 7(a) and 7(b) show the simulated and measured input impedance and return loss characteristics, respectively. The measured results agree well with the simulated ones. The real part of the impedance of the antenna at the frequency where the imaginary part is zero is equal to the antenna impedance 


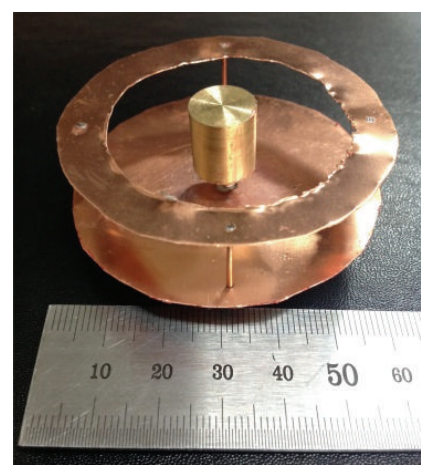

(a)

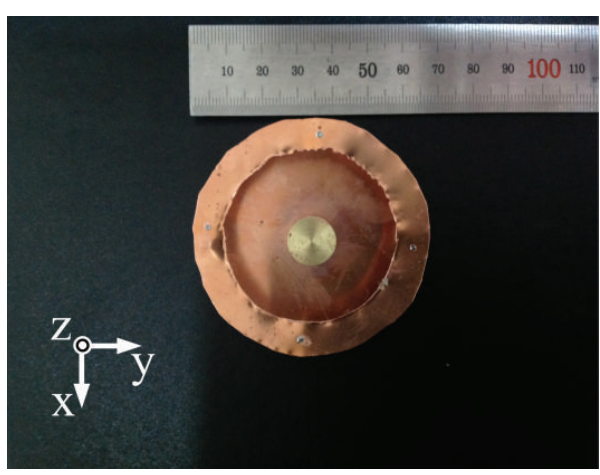

(b)

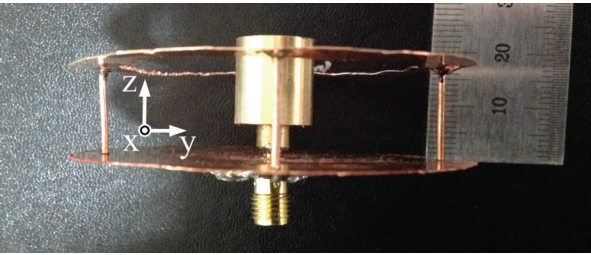

(c)

FIGURE 6: Fabricated prototype of the proposed antenna: (a) perspective view, (b) top view, and (c) side view.

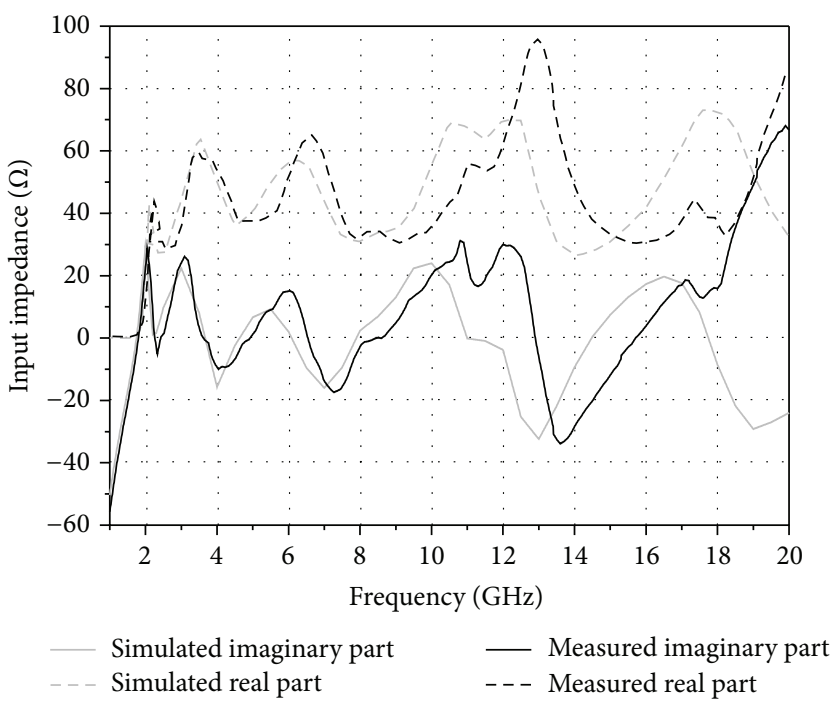

(a)

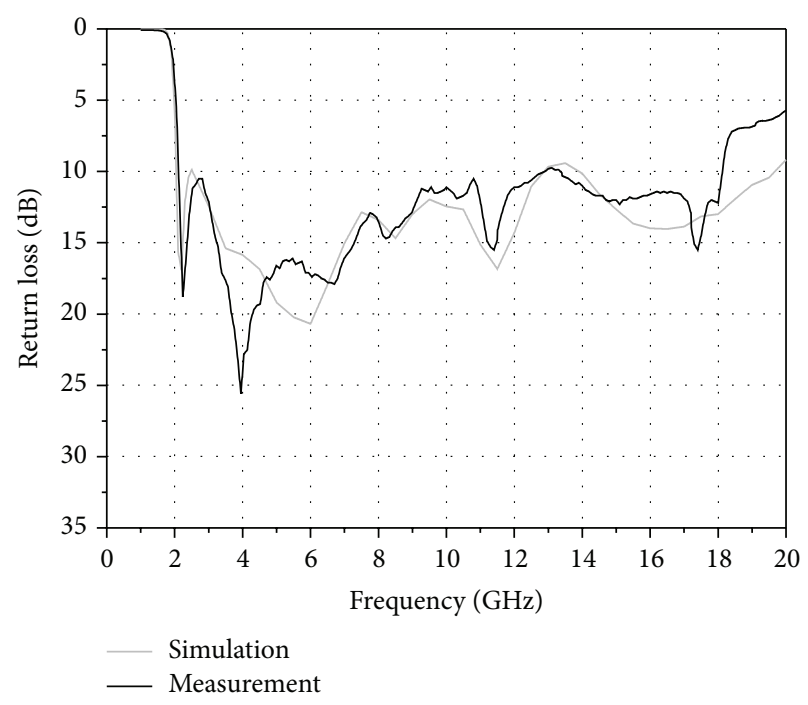

(b)

FIGURE 7: Simulated and measured input impedance and return loss results: (a) input impedance, (b) return loss.

at the resonance frequency. The feeding coaxial cable has a 50$\Omega$ characteristic impedance. The measured $10-\mathrm{dB}$ return loss bandwidth of the antenna is $11 \mathrm{GHz}(2 \mathrm{GHz}-13 \mathrm{GHz})$, which can fully cover the WiBro, WLAN, DMB, and UWB bands.

Figure 8 shows the simulated and measured far field radiation patterns in $x z$ - and $y z$-planes at $2.2 \mathrm{GHz}, 4 \mathrm{GHz}$, $6 \mathrm{GHz}, 8 \mathrm{GHz}, 10 \mathrm{GHz}$, and $12 \mathrm{GHz}$. The measured radiation pattern results agree very well with the simulated ones. The proposed antenna has vertical monopole-like radiation patterns in all operating frequencies from $2 \mathrm{GHz}$ to $12 \mathrm{GHz}$ with a low profile $\left(0.12 \lambda_{0}\right.$ at $\left.2 \mathrm{GHz}\right)$.

Figure 9 shows the simulated and measured peak gains of the proposed antenna. The measured result agrees reasonably well with the simulated one. The antenna gain varies from $0.7 \mathrm{dBi}$ to $9 \mathrm{dBi}$ over the operating frequency band.

Figure 10 shows the simulated and measured group delay characteristics against frequency. Group delay, the parameter that describes a signal transition time through a device, is important in UWB communication systems. From the results, the group delay variation is less than $1 \mathrm{~ns}$ and provides an approximately constant value over the UWB band $(3.1 \mathrm{GHz}-10.6 \mathrm{GHz})$. The measured group delay variation is less than $0.5 \mathrm{~ns}$ between $1 \mathrm{GHz}$ and $20 \mathrm{GHz}$; however, minimal discrepancy occurs between the simulated and measured results (1 ns) from $2 \mathrm{GHz}$ to $3 \mathrm{GHz}$.

\section{Conclusion}

In this letter, a stepped cylindrical antenna with a higherorder mode ring patch for wideband conical radiation pattern was proposed. The stepped cylindrical monopole and $\mathrm{TM}_{41}$ higher-order mode shorted ring patch are used for monopole-like radiation characteristics with broad bandwidth. The stepped cylindrical monopole was designed for a higher frequency band, such as UWB. Moreover, the shorted ring patch with the $\mathrm{TM}_{41}$ higher-order resonance mode was adopted to generate additional lower frequency bands, such as WiBro, WLAN, and DMB. The $10-\mathrm{dB}$ return 


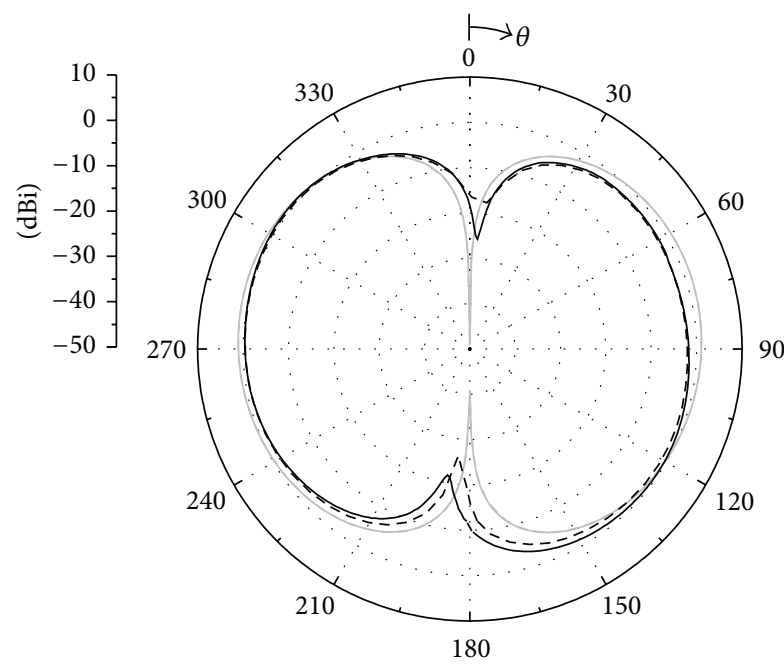

(a)

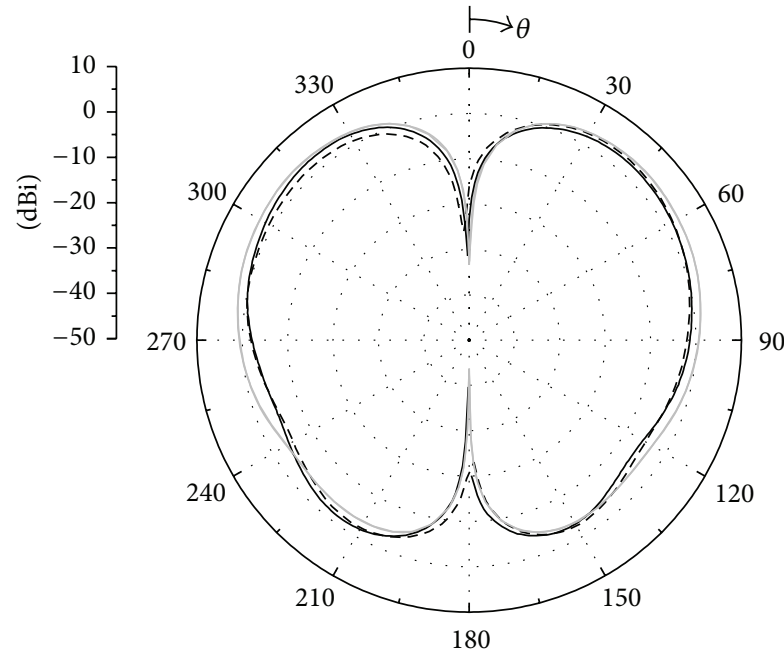

(c)

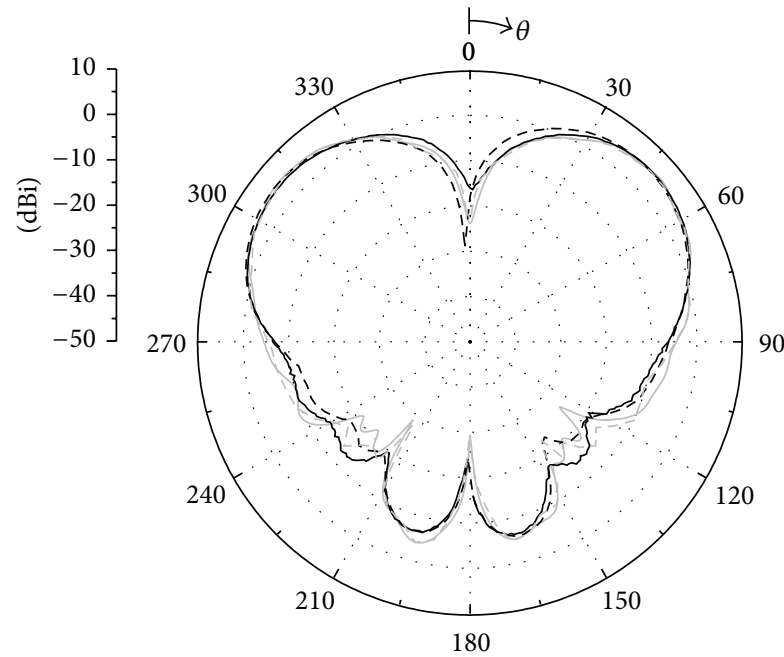

$\begin{aligned} & \text { Simulation }(x z \text {-plane }) \quad-\text { Measurement }(x z \text {-plane }) \\ & --- \text { Simulation }(y z \text {-plane })\end{aligned}--$ Measurement $(y z$-plane $)$

(e)

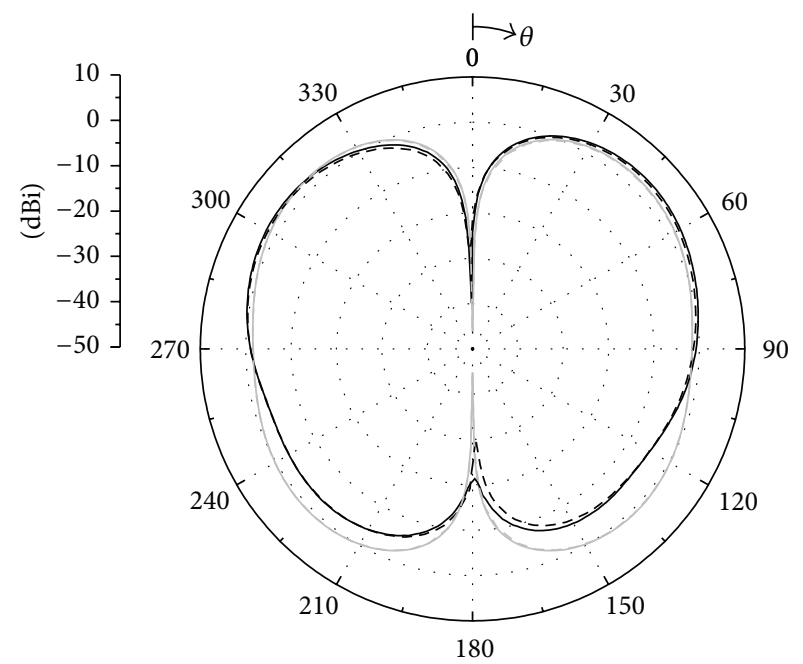

(b)

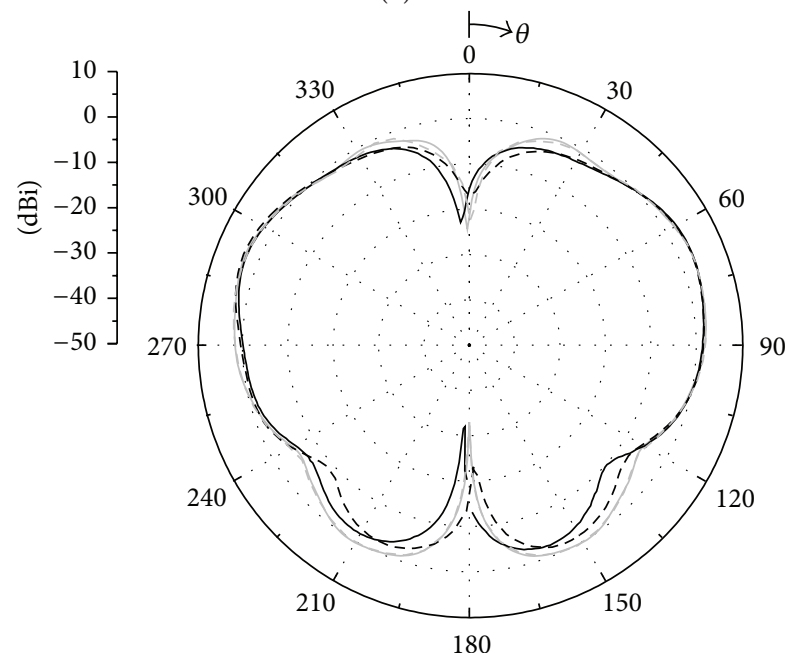

(d)

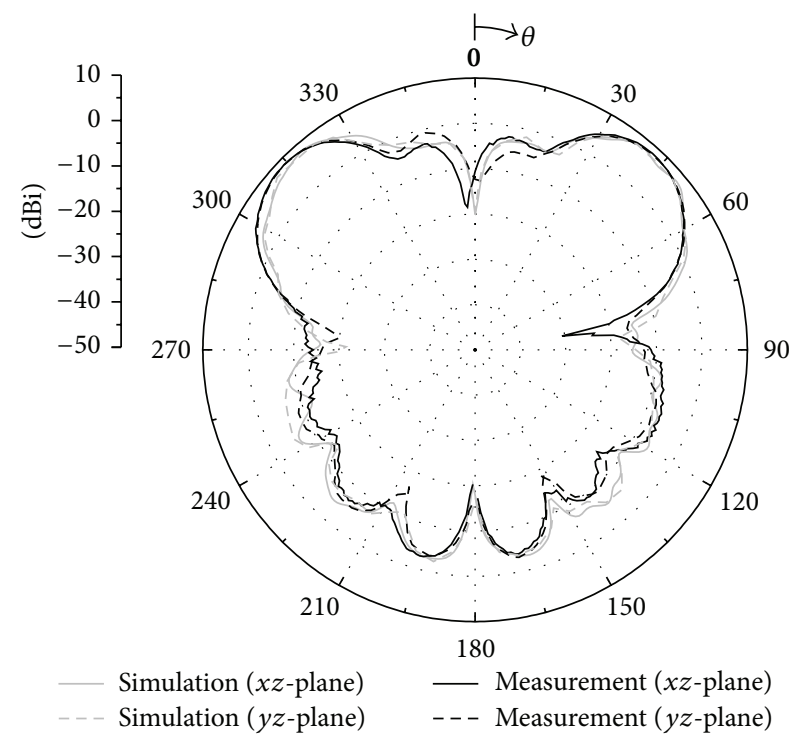

(f)

Figure 8: Simulated and measured far field radiation patterns in $x z$ - and $y z$-planes at (a) $2.2 \mathrm{GHz}$, (b) $4 \mathrm{GHz}$, (c) $6 \mathrm{GHz}$, (d) $8 \mathrm{GHz}$, (e) $10 \mathrm{GHz}$, and (f) $12 \mathrm{GHz}$. 


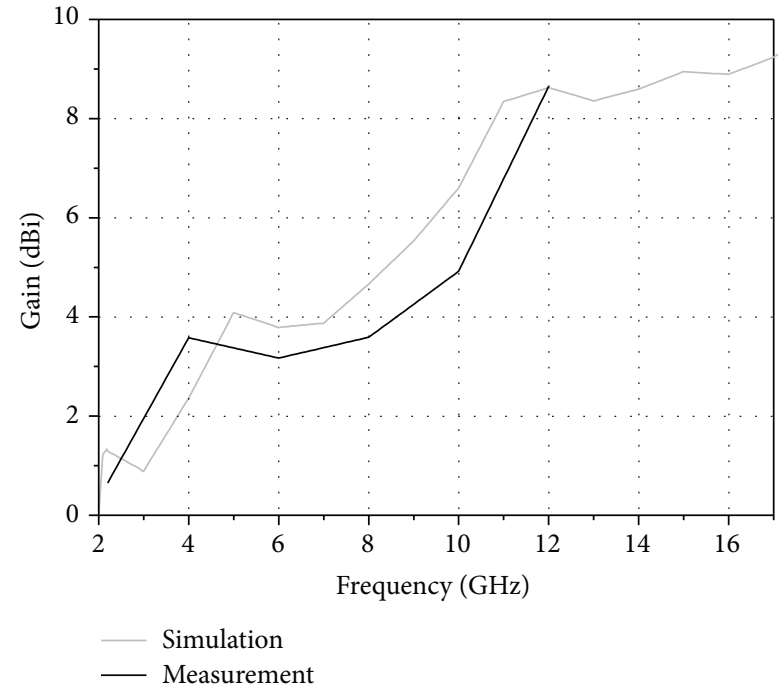

FIGURE 9: Simulated and measured peak gains of the proposed antenna.

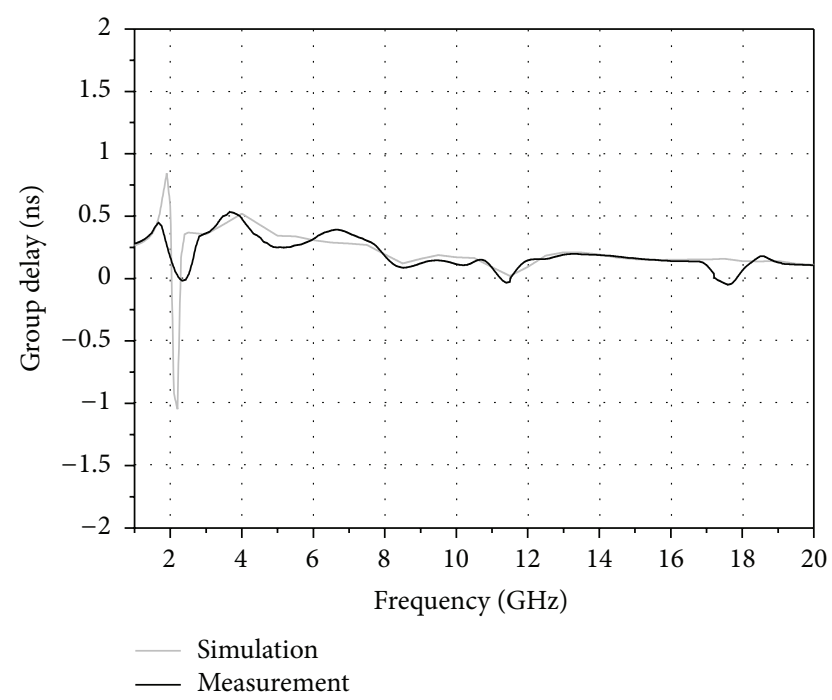

FIGURE 10: Simulated and measured group delay characteristics against frequency.

loss bandwidth is sufficiently wide to cover WiBro, three WLANs, DMB, and UWB wireless communication services. The proposed antenna has monopole-like radiation patterns in all operating frequencies with a low profile $\left(0.12 \lambda_{0}\right.$ at $2 \mathrm{GHz}$ ). The results demonstrate that the proposed antenna is well suited for various wireless communication systems.

\section{Conflict of Interests}

The authors declare that there is no conflict of interests regarding the publication of this paper.

\section{Acknowledgment}

This research was supported by the MSIP (Ministry of Science, ICT \& Future Planning), Korea, under the ITRC
(Information Technology Research Center) support program (IITP-2015-H8501-15-1006) supervised by the IITP (Institute for Information \& Communications Technology Promotion).

\section{References}

[1] W. L. Stutzman and G. A. Thiele, Antenna Theory and Design, Wiley, New York, NY, USA, 2nd edition, 1998.

[2] R. Webster, "20-70 MC monopole antennas on ground-based vehicles," IRE Transactions on Antennas and Propagation, vol. 5, no. 4, pp. 363-368, 1957.

[3] M. Cerretelli, V. Tesi, and G. B. Gentili, "Design of a shapeconstrained dual-band polygonal monopole for car roof mounting," IEEE Transactions on Vehicular Technology, vol. 57, no. 3, pp. 1398-1403, 2008.

[4] C. Delaveaud, P. Leveque, and B. Jecko, "New kind of microstrip antenna: the monopolar wire-patch antenna," IEEE Electronics Letters, vol. 30, no. 1, pp. 1-2, 1994.

[5] J. Tak, K. Kwon, S. Kim, and J. Choi, "Dual-band on-body repeater antenna for in-on-on WBAN applications," International Journal of Antennas and Propagation, vol. 2013, Article ID 107251, 12 pages, 2013.

[6] J. Tak and J. Choi, "Circular-ring patch antenna with higher order mode for on-body communications," Microwave and Optical Technology Letters, vol. 56, no. 7, pp. 1543-1547, 2014.

[7] C. A. Balanis, Antenna Theory: Analysis and Design, Wiley, New York, NY, USA, 3rd edition, 1997.

[8] S. Kundu, M. Kundu, and K. Mandal, "Small monopole antenna with corner modified patch for UWB applications," in Proceedings of the 1st International Conference on Automation, Control, Energy and Systems (ACES '14), pp. 1-3, Hooghly, India, February 2014

[9] M. Manohar, R. S. Kshetrimayum, and A. K. Gogoi, "Printed monopole antenna with tapered feed line, feed region and patch for super wideband applications," IET Microwaves, Antennas and Propagation, vol. 8, no. 1, pp. 39-45, 2014.

[10] G. Teni, N. Zhang, and J. Qiu, "Research on a novel folded monopole with ultrawideband bandwidth," IEEE Antennas and Wireless Propagation Letters, vol. 13, pp. 802-805, 2014.

[11] J.-C. Chun, "Wideband cylindrical monopole antenna for multiband wireless applications," Microwave and Optical Technology Letters, vol. 51, no. 1, pp. 15-17, 2009.

[12] K.-L. Wong and S.-L. Chien, "Wide-band cylindrical monopole antenna for mobile phone," IEEE Transactions on Antennas and Propagation, vol. 53, no. 8, pp. 2756-2758, 2005.

[13] R. Garg, P. Bhartia, I. Bahl, and A. Ittipiboon, Microstrip Antenna Design Handbook, Artech House, Norwood, Mass, USA, 2001. 

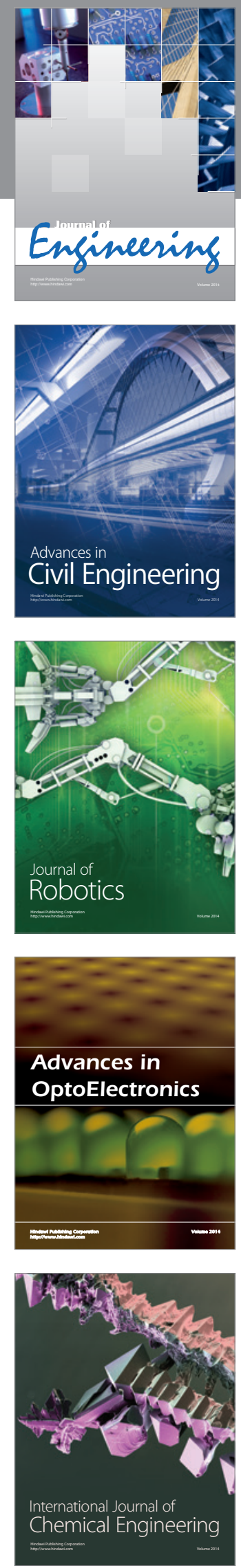

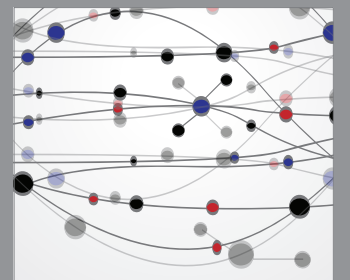

The Scientific World Journal
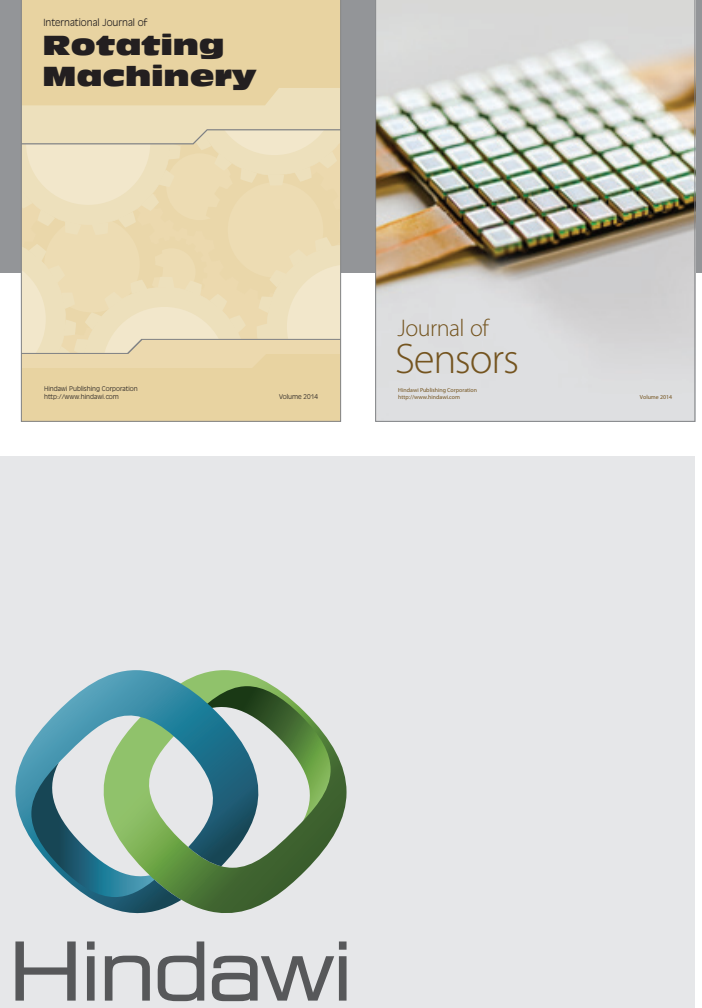

Submit your manuscripts at http://www.hindawi.com
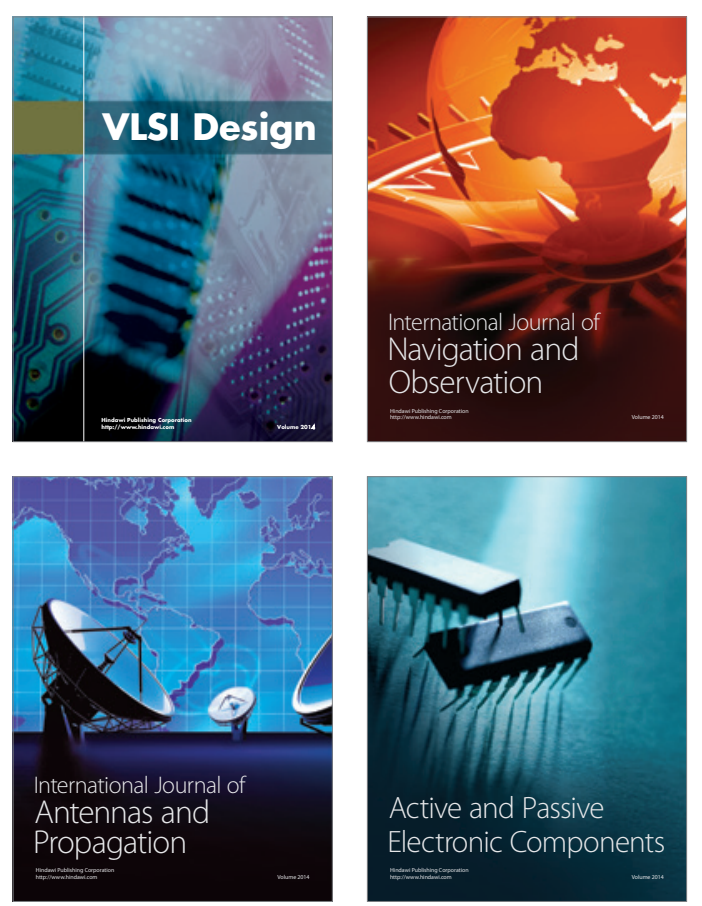
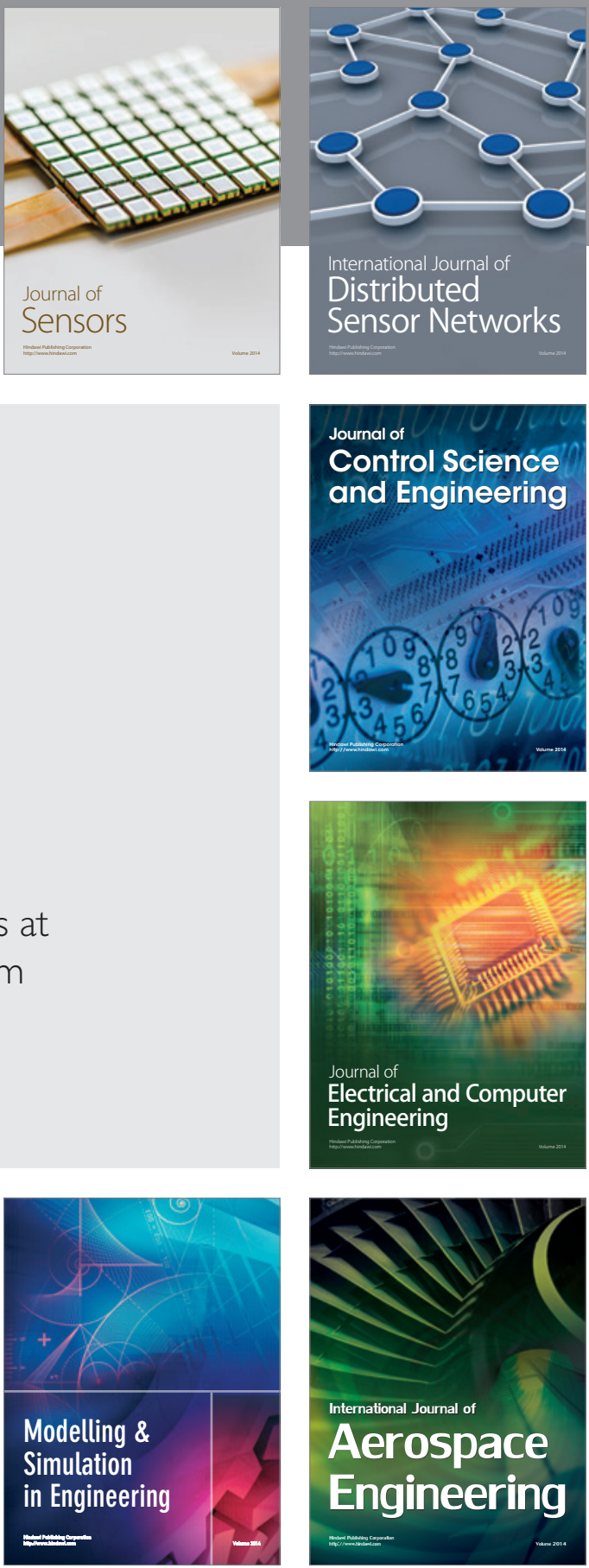

Journal of

Control Science

and Engineering
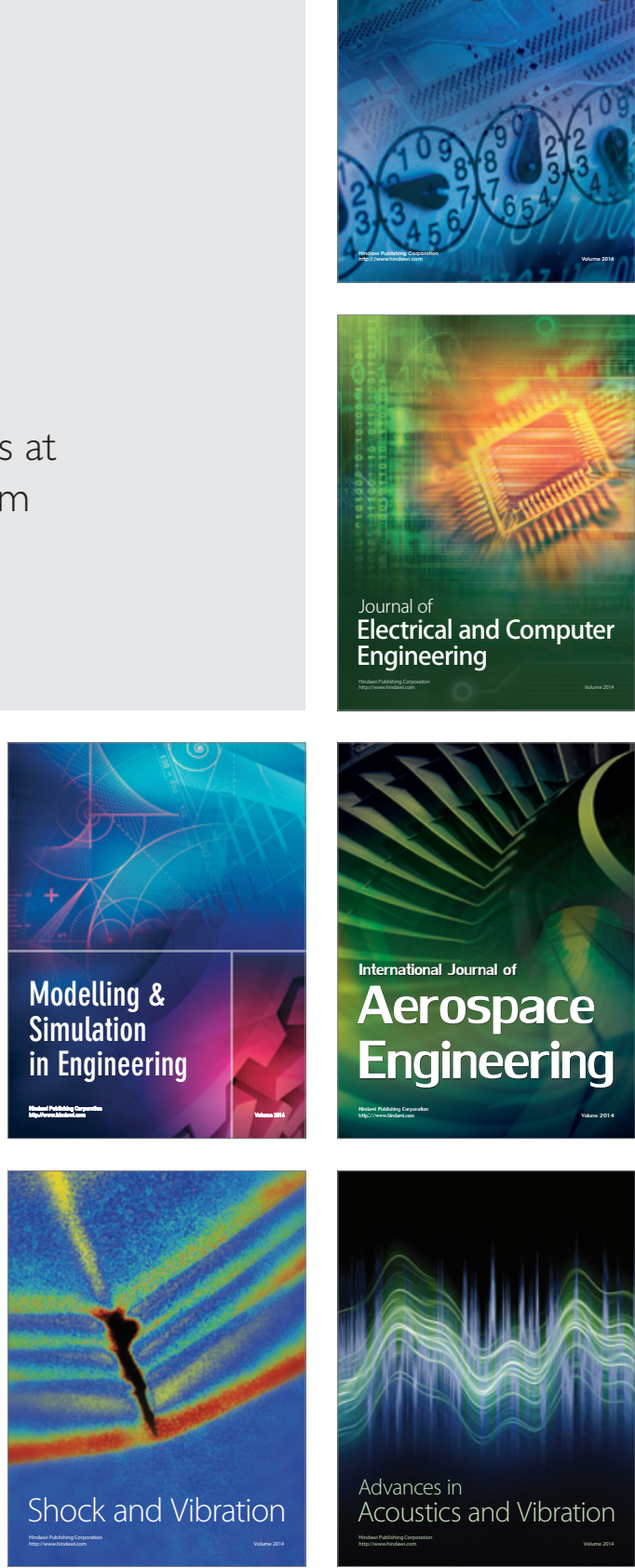